\title{
Assessment of Foam for Deep Flow Diversion
}

\author{
Goodyear S. G., Jones P. L. R.
}

AEA Technology, Winfrith, U. K.

\begin{abstract}
Copyright 1995. Steering Committoe of the European IOR - Symposium.
This paper was presented at the Oth. European IOR - Symposium in Vionna, Austria, May 16 - 17. 1996

This paper was solected for presentation by the Steering Committeo, following review of information contained in an abstract

cubmitted by the author(s). The paper, as presented has not been reviewed by the 5 taering Committee.
\end{abstract}

\begin{abstract}
Foam injection has a number of possible applications as an IOR technique. Laboratory studies of foam flow in porous media suggest that relative foam mobility is approximately inversely proportional to permeability. This means that foam has potential as a flow diversion agent, in principle sweeping low permeability regions as aifectively as high permeability regions.
\end{abstract}

The application of foam to correct permeability contrasts has been investigated using a producer injector pair in a generic model of the North Sea Rannoch-Etive sands, in which there is a significant permeability contrast between the main reservoir lavers. Foam flooding has been assessed with the SCORPIO chemical flooding simulator, which uses a semi-empirical steady state foam mobility model

A number of foam injection strategies were considered, including pre-injection of surfactant solution. The simulations showed that foam could improve recovery compared to water flooding, by a combination of flow diversion and improved microscopic sweep. However, the simulations highlighted a number of technical issues that need to be addressed in planning for any field implementation of the technology. It was found that gravity slumping of the surfactant solution made it difficult to maintain a good foam at the top of the reservoir, where gas override is most likely. This could be overcome by increasing the foam strength, but at the expense of increased injection pressures, even though shear thinning of the foam in the near well region was taken fully into account. With realistic injector pressure limits it would be difficult to implement a successfiul foam flood in this scenario with $\mathrm{N}$ Sea well spacings.

\section{INTRODUCTION}

Foam injection has a number of possible applications as an IOR technique. These include improving areal and vertical sweep efficiency, blocking and diverting gas from high permeability zones or fractures, and treating production wells suffering from high GORs [1]. This paper focuses on the possible application of foams as flow diversion agents.

Foams increase the effective viscosity of the gas phase through thin, surfactant stabilised liquid films, that bridge across pores, impeding the gas flow. The rheology of foams in porous media is complex. depending on the surfactant used. the foam Darcy velocity and the rock properties. The dependence of foam mobility on rock properties in particular is addressed in this paper. Many laboratory studies of foam flow have shown that foam relative mobility decreases with absolute permeability, a result that can be explained theoretically in terms of the relationship between liquid film disjoining pressure and capillary pressure [2]. As a first approximation this permeability dependence can make the total foam mobility (i.e. the product of absolute permeability and foam relative mobility) almost independent of permeability. This makes foams potentially useful as flow diversion agents since, in principle, they will selectively retard flow in higher permeability layers. in addition to possible 
benefits from lowered residual oil saturations in the regions accessed by the foam.

This paper describes a scoping study of foam flooding for flow diversion in a generic model of the North Sea Rannoch-Etive sequence, in which the high permeability contrast between the Rannoch and Etive can lead to early water breakthrough in the Etive and poor sweep of the Rannoch. This study focuses on indepth treatments, since it is assumed that more limited near well bore treatments would be accomplished using gel treatments or conventional recompletion methods. A simple analytical model is used to highlight the benefits of a permeability selective mobility control agent, such as a foam. The specific application of foam is then investigated using a SCORPIO cross-section model. Foam mobilities are modelled using a semiempirical approach [3] based on the concept of critical foam disjoining pressures. The results of the simulations are presented and the key issues of gravity segregation and foam injectivity are highlighted.

\section{PERMEABLITY-SELECTIVE MOBLITY REDUCTION}

This section describes a simple analytical model that gives a first indication of the benefits of permeabilityselective flow diversion agents such as foams. compared to more conventional mobility reducing agents such as polymers.

The model consist of two non-communicating uniform layers with a permeability contrast between them, Figure 1.

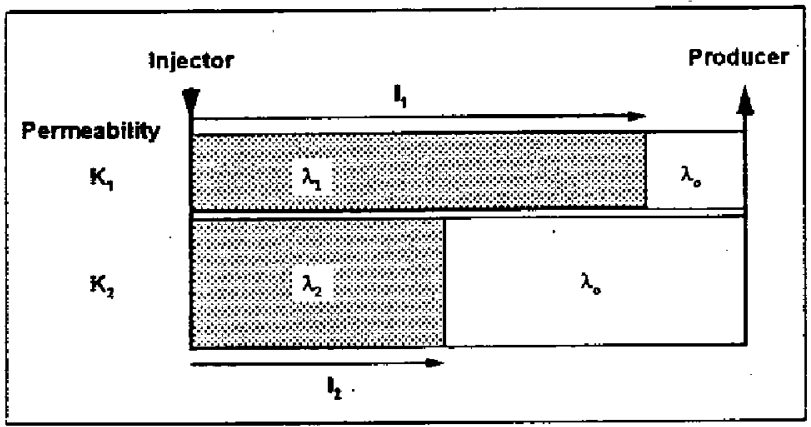

Figure 1: Schematic Diagram of Analytical Two Layer Model

The displacement is assumed to be piston-like in each layer irrespective of the fluid injected. Different mobilities for the oil and the displacing fluid in the two layers are assumed. This allows the effect of injecting a fluid with permeability-dependent mobilities to be considered. The injection of fluid into the lavers is determined by assuming a constant total injection rate and the same pressure drop between the producer and injector in each layer.
For simplicity the effects of the initial water saturation and adsorption of any mobility control agentits is neglected, although these effects could in principle be included. Working in terms of dimensionless variables, with the reservoir length and total thickness normalised to one, and time expressed in movable hydrocarbon pore volumes, the differential equation prior to breakthrough relating the dimensionless distance travelled by the displacement fronts in the two layers is given by:

$\frac{1}{k_{1}}\left(\frac{l_{1}}{\lambda_{1}}+\frac{1-l_{1}}{\lambda_{0}}\right) \frac{d l_{1}}{d t}=\frac{1}{k_{2}}\left(\frac{l_{2}}{\lambda_{2}}+\frac{1-l_{2}}{\lambda_{0}}\right) \frac{d l_{2}}{d t}$

where the symbols are defined in the nomenclature and the normalised layer thicknesses satisfy $h_{1}+h_{2}=1$. This has the solution:

$\frac{1}{k_{1}}\left(\frac{1}{\lambda_{1}}-\frac{1}{\lambda_{0}}\right) l_{1}{ }^{2}+\frac{2 l_{1}}{\lambda_{0} k_{1}}=\frac{1}{k_{2}}\left(\frac{1}{\lambda_{2}}-\frac{1}{\lambda_{0}}\right) l_{2}^{2}+\frac{2 l_{2}}{\lambda_{0} k_{2}}(2)$

from which the distance flooded in the lower permeability layer at breakthrough in the higher permeability layer can be calculated from:

$\frac{1}{k_{2}}\left(\frac{1}{\lambda_{2}}-\frac{1}{\lambda_{0}}\right) l_{2}^{* 2}+\frac{2}{\lambda_{0} k_{2}} l_{2}^{*}-\frac{1}{k_{1}}\left(\frac{1}{\lambda_{1}}+\frac{1}{\lambda_{0}}\right)=0$

where the breakthrough time and fractional movable oil recovery is given by $h_{1}+l_{2}^{*} h_{2}$. After breakthrough in laver 1 the progression of the flood in layer 2 is governed by

$\left\{\frac{l_{2}}{k_{2}}\left(\frac{1}{\lambda_{2}}-\frac{1}{\lambda_{o}}\right)+\frac{1}{\lambda_{0} k_{2}}+\frac{h_{2}}{h_{1} \lambda_{1} k_{1}}\right\} \frac{d l_{2}}{d t}=\frac{1}{h_{1} \lambda_{1} k_{1}}$

which has the solution relating time and the distance flooded in laver 2 given by

$$
\begin{aligned}
\frac{2 t}{h_{1} \lambda_{1} k_{1}}= & \frac{1}{k_{2}}\left(\frac{1}{\lambda_{2}}-\frac{1}{\lambda_{0}}\right) l_{2}{ }^{2} \\
& +2\left(\frac{1}{\lambda_{0} k_{2}}+\frac{h_{2}}{h_{1} \lambda_{1} k_{1}}\right) l_{2}+\frac{1}{k_{1}}\left(\frac{1}{\lambda_{1}}-\frac{1}{\lambda_{0}}\right)
\end{aligned}
$$

with the cumulative recovery given by $h_{1}+l_{2} h_{2}$ (for $\left.l_{2} \leq 1\right)$

The application of this model is illustrated for the case where the two lavers are of equal thickness, but where there is a contrast of a factor of ten between the permeabilities. The water flood is assumed to be a unit mobility displacement. This is compared with a flood where the mobility is reduced by a factor of ten compared to water in both layers (corresponding to a 
continuous polymer flood) and a flood where the mobility is reduced by a factor of ten in the high permeability layer, but left the same as water in the low permeability layer (corresponding to a continuous foam flood). The "foam" flood therefore shows a selective mobility reduction in the-higher permeability material, with a total mobility that is independent of permeability.

The corresponding cumulative oil recovery and oil cut up to 2 MHPV injection are shown in Figures 2 and 3 respectively. The water flood shows the expected early water breakthrough at $0.55 \mathrm{MHPV}$, with production after this time at a $9 \%$ oil cut, giving a cumulative recovery of $0.68 \mathrm{MHPV}$ after $2 \mathrm{MHPV}$ injection. The "polymer" flood shows a delay in the breakthrough time to $0.63 \mathrm{MHPV}$ with a cumulative recovery of 0.88 MHPV after 2 MHPV injection, the oil cut at this point being $12 \%$. The "foam" flood shows the best performance with breakthrough delayed to $0.78 \mathrm{MHPV}$. after which oil production continues at $50 \%$ oil cut, so that all the movable oil is produced by $1.22 \mathrm{MHPV}$ injection.

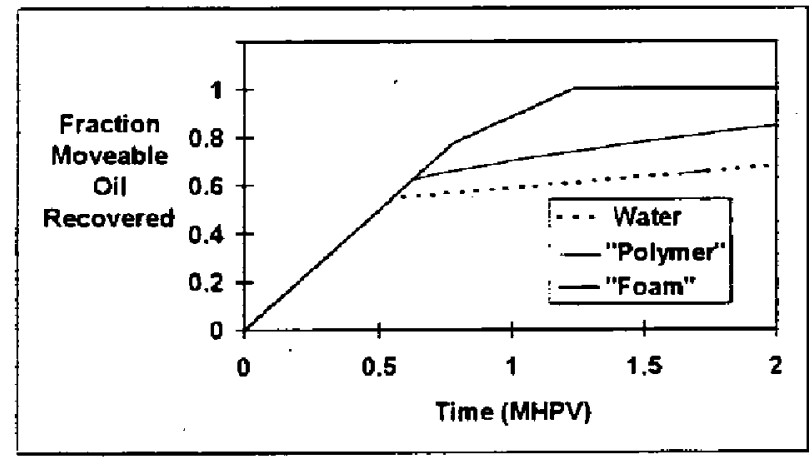

Figure 2: Cumulative Oil Recovery Calculated from Analytical Model

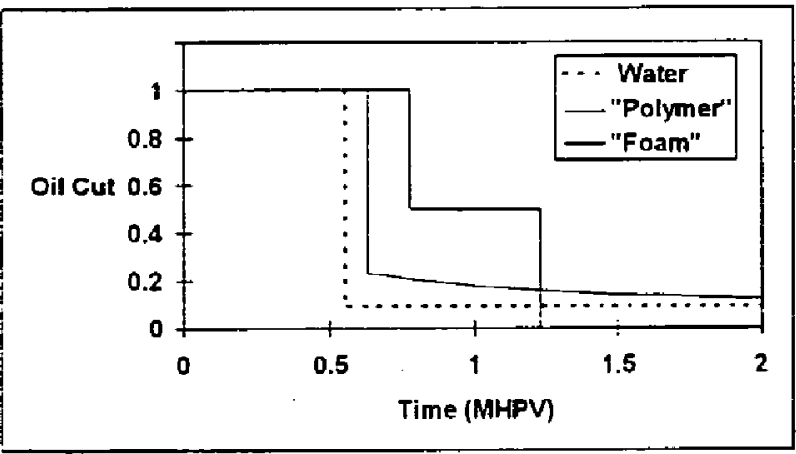

Figure 3: Oi! Cut Calculated from Analytical Model

These simple calculations highlight the possible benefits from selective mobility reduction as a function of permeability and justify a more detailed investigation of the potential for this process. However, a number of issues need $\because$ be addressed when considering the application of ivam using more realistic models:

- the influence of communication between reservoir lavers
- the influence of gravity

- the effect of surfactant adsorption and the initial water saturation

- the placement of the surfactant solution.

- The next two sections describe the implementation of a foam flooding option in the SCORPIO chemical flooding simulator and its application in cross-sectional studies of foam injection

\section{FOAM MODELLING IN SCORPIO}

One approach to the simulation of foam flow is the population balance model [4], in which foam mobilities are deduced from first principles using pore scale models for bubble generation, coalescence and movement. At this level many parameters are needed to describe the pore-scale phenomena which are the subject of ongoing research. If the bubble population balance model is to be used at a more pragmatic level, adjusting the parameters of the model to fit data, the model has many degrees of freedom, resulting in a poor predictive capacity.

An alternative approach to transient modelling of foam flow is to use steady state foam phase mobilities, that can be measured directly from core flooding experiments, in a conventional multi-component simulator. This is entirely analogous to using relative permeabilities to model transient oil-water flow, rather than population balance models for oil ganglia. This is the approach adopted in this study with a steady state foam flow model being implemented in the SCORPIO simulator [5].

Experiments in unconsolidated porous media $[2,6]$ show that foam flow is often in the foam coalescence regime, in which increased gas flow is accommodated by a balance between a constant foam generation rate and an increased foam destruction rate, sufficient to maintain the capillary pressure at a fixed critical value and corresponding water saturation [2]. This leads in one dimension. on application of Darcy's law, to a simple expression for the gas relative mobility in terms of fractional flow:

$$
\lambda_{r g}=\lambda_{r a}^{*} \frac{f_{g}}{1-f_{g}}
$$

where $\lambda_{r a}^{*}$ is the fixed aqueous phase mobility.

In consolidated porous media there will be a wider distribution of pore sizes leading to a relativeis inhomogeneous medium at the pore scale. When applied to such a system, the dynamic lamella rupture model of [7] gives a range of capillary pressures over which moving lamellae will rupture. The expression for foam relative mobilities for unconsolidated porous 
thiedia was generalised through the introduction of a foam coalescence exponent $\boldsymbol{n}$ to:

$$
\lambda_{r g}=\lambda_{r g}^{*}\left(\frac{\lambda_{r a}^{*}}{\lambda_{r a}}\right)^{n}
$$

where $\lambda_{r g}^{*}$ is the relative gas mobility at a reference fractional flow $f_{g}^{*}$ and $\lambda_{r a}^{*}$ is the corresponding relative aqueous mobility. This was found to provide a good match to steady state data reported in the literature [4].

The gaseous and aqueous mobilities at the reference fractional flow are related by:

$$
f_{g}^{*}=\frac{\lambda_{r g}^{*}}{\lambda_{r a}^{*}+\lambda_{r g}^{*}}
$$

Combining Equations 7 and 8 gives the foam gas mobility as:

$$
\lambda_{r g}=\lambda_{r g}^{*}\left(\frac{\lambda_{r g}^{*}}{\lambda_{r a}} \frac{1-f_{g}^{*}}{f_{g}^{*}}\right)^{n}
$$

The model as implemented in SCORPIO assumes a constant value for $f_{g}^{*}$, but allows the foam coalescence exponent and critical relative gas mobility to depend on gas velocity, oil saturation. temperature, gas pressure. gas effective permeability and component concentrations in the aqueous phase, defined through tabular input. The foam model ensures a continuous transition from the foam mobility model to the ordinary gas mobility as the surfactant concentration tends to zero. For surfactant concentrations below the minimum concentration defining the foam coalescence exponent and critical relative gas mobility, linear interpolation is used between the foam mobility calculated at the minimum surfactant concentration and the original gas mobility. In some cases the foam model may calculate a notional gas mobility above the basic gas mobility defined by the gas relative permeability and viscosity. In inese circumstances the foam mobility model defaults to the original gas mobility calculation.

\section{FOAM FLOODING SLMULATIONS}

This section describes the generic cross-section model of the Rannoch-Etive sequence used in the simulations before presenting the results of the foam injection simulations.

\section{Description of model}

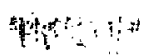

The model consists of three uniform layers each with a thickness of $50 \mathrm{ft}$, with no transmissibility barriers between them. The upper layer, with a permeability of 3000 md corresponds to the Etive, while the middle $(200 \mathrm{md})$ and lower $(50 \mathrm{md})$ layers correspond to the lower permeability Rannoch, Figure 4.

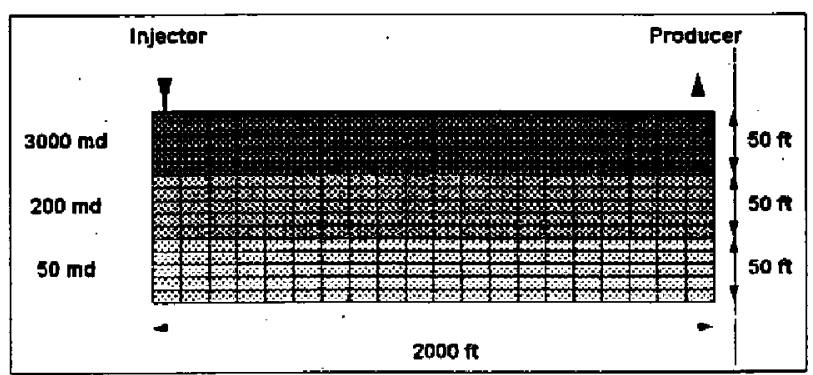

Figure 4: Schematic Diagram of SCORPIO Rannoch-Etive Model

The length of the model was $2000 \mathrm{ft}$, with a width of $1400 \mathrm{ft}$. The injection rate was $10,000 \mathrm{bbl} / \mathrm{day}$ with the producer constrained at a BHP of $3275 \mathrm{psi}$ at the bottom of the Rannoch. The base case version of the model had a $k_{v}: k_{h}$ of 0.1 and was initialised to a uniform initial oil saturation of $85 \%$ (no capillary pressure was included in the model). The ultimate water flood residual oil saturation as defined by the relative permeabilities was set to $25 \%$. A regular horizontal grid of 20 blocks with each geological layer divided into 5 blocks vertically was found to be adequate by comparing results from this grid with grids refined in the horizontal and vertical directions. In all cases the simulations were nun to 10 years.

The foam mobility was modelled using the method described in the previous Section. The gas mobility at a reference fractional flow of 0.5 was defined to have a gas Darcy velocity dependence according to:

$$
\lambda_{r g}^{*}=\lambda_{r g 1}^{*}+\lambda_{r g 2}^{*} u_{g}
$$

where the dependence of $\lambda_{r g 1}^{*}, \lambda_{r g 2}^{*}$ and the foam coalescence exponent on concentration in the Etive layer are defined in Table 1.

\section{Table 1: Foam Mobility Parameters}

\begin{tabular}{|c|c|c|c|}
\cline { 2 - 4 } \multicolumn{1}{c|}{} & \multicolumn{3}{c|}{ Surfactant Concentration (wt\%) } \\
\hline Parameter & 0.05 & 0.1 & 0.5 \\
\hline$\lambda_{r g 1}^{*}(1 / P a . s)$ & 9.74 & 2.92 & 1.17 \\
\hline$\lambda_{r g 2}^{*}(1 / P a . m)$ & $1.84 \times 10^{5}$ & $8.29 \times 10^{4}$ & $3.32 \times 10^{4}$ \\
\hline $\mathrm{n}$ & 4 & 1 & 1 \\
\hline
\end{tabular}

The foam mobility in the Rannoch layers has the same dependence on surfactant concentration and gas 
velocity as defined in Equation 10 and Table 1, the only difference being that the mobility is increased in inverse proportion to the permeability contrast between the Rannoch and Etive.

\section{Base Case Foam Injection Strategy}

To simplify the model all the phases were assumed to be incompressible. This had the advantage of allowing cases to be compared on an equivalent basis even in circumstances in which significant pressure gradients were generated. Injection of gas was assumed to reduce the residual oil saturation defined by the relative permeabilities to $10 \%$ in the presence of connate water, although in the absence of foam this value is not achieved in the simulations. The foam was modelled using the parameter values given in Table 1 . The surfactant was assumed to adsorb with a Langmuir isotherm with a maximum value of $0.1 \mathrm{mg} / \mathrm{g}$.

Previous studies of foam flooding in one dimension [4] showed that it was important to pre-inject surfactant solution to minimise gas breakthrough ahead of the foam front, since this would delay the production of incremental oil. Bearing this in mind the following foam injection strategy was devised:

- injection of $0.8 \mathrm{wt} \%$ surfactant solution for 62 days (sufficient to satisfy adsorption in the Etive layer)

- injection of foam to block the Etive layer near the injector (reservoir foam quality $98.3 \%$ and aqueous surfactant concentration of $0.4 \mathrm{wt} \%$ )

- injection of $0.8 \mathrm{wt} \%$ surfactant for 62 days (sufficient to satisfy adsorption in the upper Rannoch layer)

- continuous injection of foam (reservoir foam quality $98.3 \%$ and aqueous surfactant concentration of $0.4 \mathrm{wt} \%$ )

This predominantly continuous injection of foam contrasts with the surfactant assisted alternating water and gas technique (SAGA) [8], that has been proposed for stratified reservoirs similar to those considered in this paper.

The cumulative oil production for the water flood and the foam flood are shown in Figure 5 where, for completeness, the result of gas injection without surfactant is also shown. The results are summarised in Table 2. The foam flood is seen to perform significantly better than the water flood, with an increment of 2.87 MMSTB after ten years production. Most of the incremental oil is produced very early in the foam flood, between one and three years from the start of foam injection.

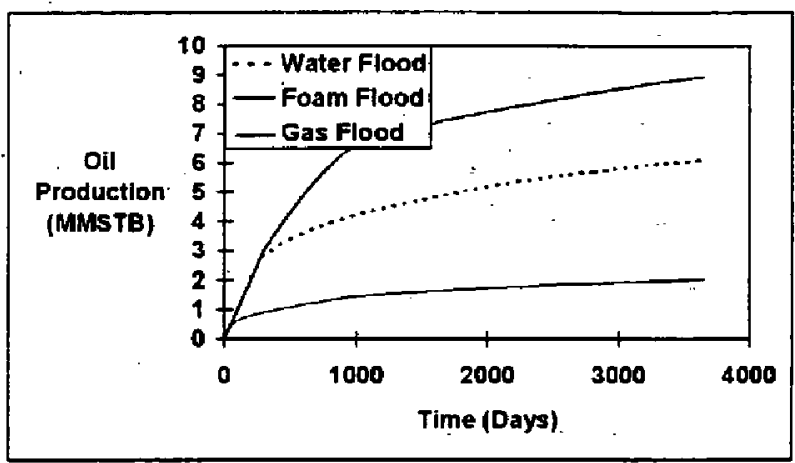

Figure 5: Cumulative Oil Recovery for Base Case Water, Foam and Gas Injection Simulations

Figure 6 shows the gas saturations and surfactant concentrations at 244,730 and 1825 days for the foam flood. This shows that the foam has produced a relatively uniform vertical sweep by the gas, despite the high permeability contrasts between the three layers. The surfactant solution shows evidence of gravity slumping within the Etive layer. This tends to weaken the foam at the top of the Etive layer, allowing gas to override and breakthrough. Without this gravity slumping in the placement of the pre-injected surfactant, the foam would have performed better, with gas breakthrough being further delayed

Table 2: Summary of Simulation Cases

\begin{tabular}{|l|c|c|c|c|c|c|c|}
\hline \multicolumn{1}{|c|}{ Case } & $\begin{array}{c}\text { Oil } \\
\text { Production } \\
\text { (MMSTB) }\end{array}$ & IOR & $\begin{array}{c}\text { Surfactant } \\
\text { Injected } \\
\text { (MMSTB) }\end{array}$ & $\begin{array}{c}\text { Net Gas } \\
\text { Injected } \\
\text { (Bscf) }\end{array}$ & $\begin{array}{c}\text { Surfactant } \\
\text { Efficiency } \\
\text { (STB/b) }\end{array}$ & $\begin{array}{c}\text { Net Gas } \\
\text { Efficiency } \\
\text { (STB/Mscf) }\end{array}$ & $\begin{array}{c}\text { Maximum } \\
\text { Pressure } \\
\text { (psi) }\end{array}$ \\
\hline Base Water Flood & 6.09 & - & - & - & - & - & 3405 \\
\hline Base Foam Flood & 8.96 & 2.87 & 4.64 & 6.65 & 0.62 & 0.43 & 6500 \\
\hline $\begin{array}{l}\text { Foam Flood } \\
\text { Reduced Strength }\end{array}$ & 8.26 & 2.17 & 4.64 & 5.89 & 0.47 & 0.37 & 4250 \\
\hline $\begin{array}{l}\text { Foam Flood } \\
\text { Sorg=0.25 }\end{array}$ & 7.63 & 1.54 & 4.64 & 5.56 & 0.33 & 0.28 & 6625 \\
\hline $\begin{array}{l}\text { Water Flood } \\
\text { Reduced } k_{\mathrm{v}}: k_{\mathrm{h}}\end{array}$ & 5.46 & - & - & - & - & - & 3450 \\
\hline $\begin{array}{l}\text { Foam Flod } \\
\text { Reduced } \mathrm{k}_{\mathrm{v}}: \mathrm{k}_{\mathrm{h}}\end{array}$ & 9.37 & 3.91 & 4.64 & 7.26 & 0.84 & 0.54 & 7425 \\
\hline
\end{tabular}




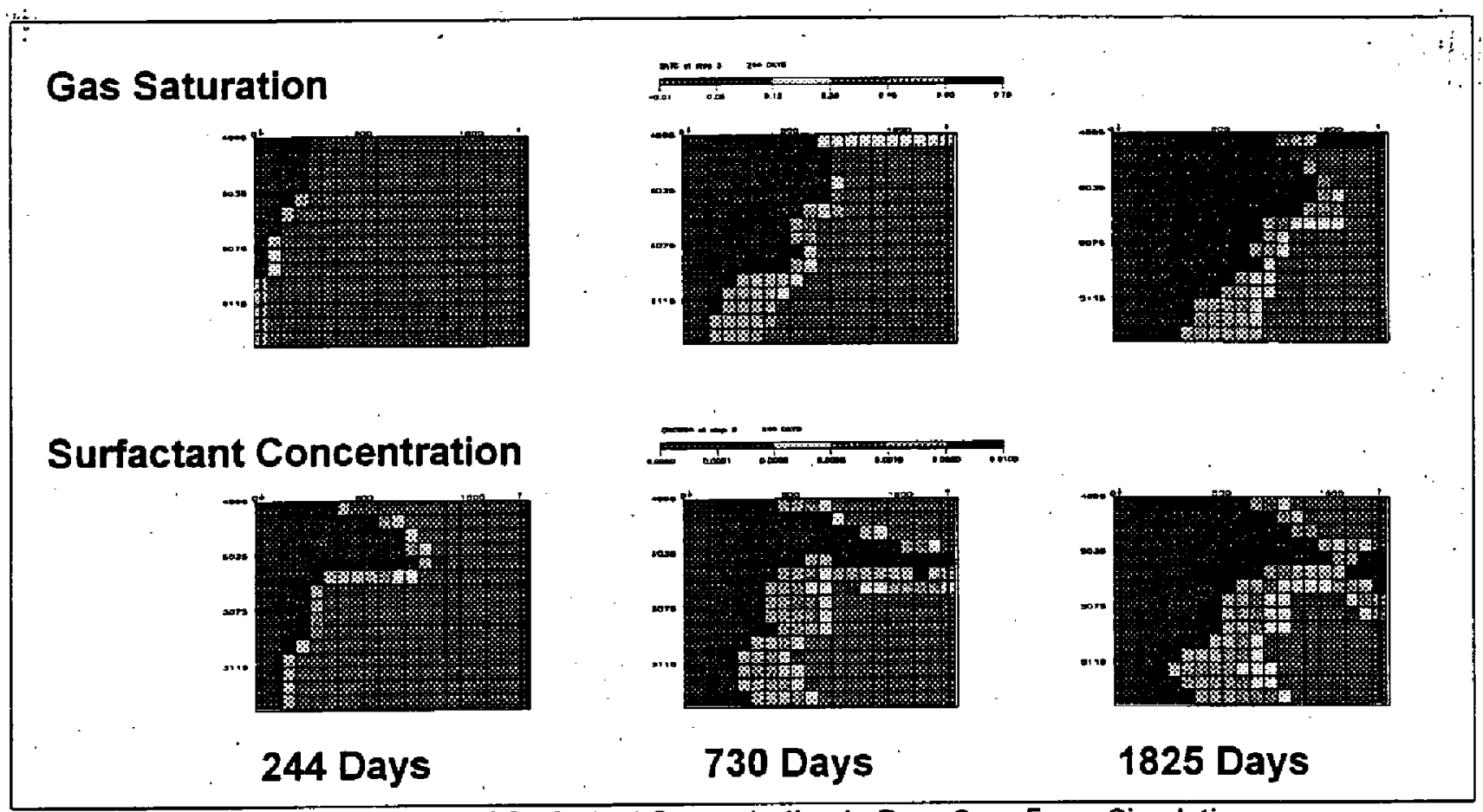

Figure 6: Gas and Surfactant Concentration in Base Case Foam Simulation

The total surfactant injected is 4.64 MMlbs and the net gas requirement is 6.65 Bscf, giving efficiencies of 0.62 STB/lb surfactant and 0.43 STB/Mscf gas. The cumulative produced surfactant is illustrated in Figure 7 , which shows that only a small fraction of the injected surfactant is produced, as would be expected, since the total mass of surfactant injected corresponded to the adsorption capacity of the Elive and upper Rannoch laver. If a full treatment of the reservoir is to be achieved there is little scope to reduce the surfactant requirement. The GOR (based on free gas production) is shown in Figure 8. There may be scope to reduce the gas handling requirement by switching to a water chase flood after foam injection has been continued for the first three years.

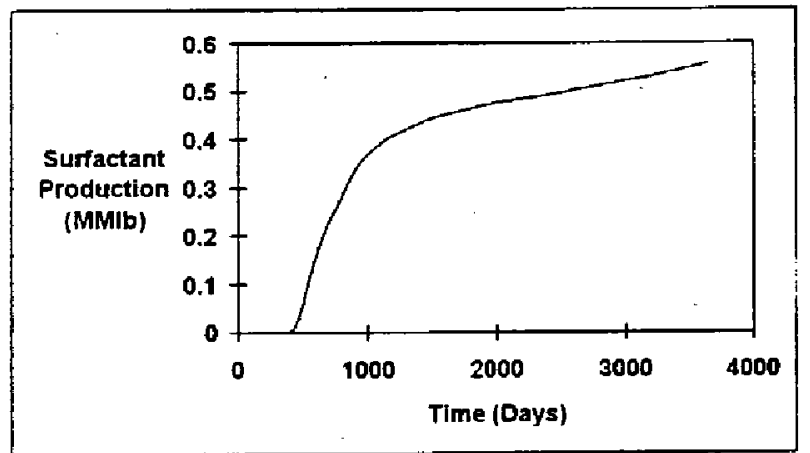

Figure 7: Produced Surfactant in Foam Base Case

The performance of the foam at this stage looks quite promising. However, an inspection of the pressures generated (Figure 9) shows that pressures in the injector grid blocks are raised to $6500 \mathrm{psi}$, compared to values in the waterflood of only $3405 \mathrm{psi}$. This highlights that injectivity is a problem threatening the technical viability of the technique. The pressures shown in Figure 9 do not include the pressure drop between the injector and the grid block. Foam is shear thinning and so it is necessary to assess the influence of this on the well to grid block pressure drop. Calculations indicate an additional pressure of approximately $1200 \mathrm{psi}$ which is significant, but small compared to the value that would be calculated if shear thinning were not taken into account.

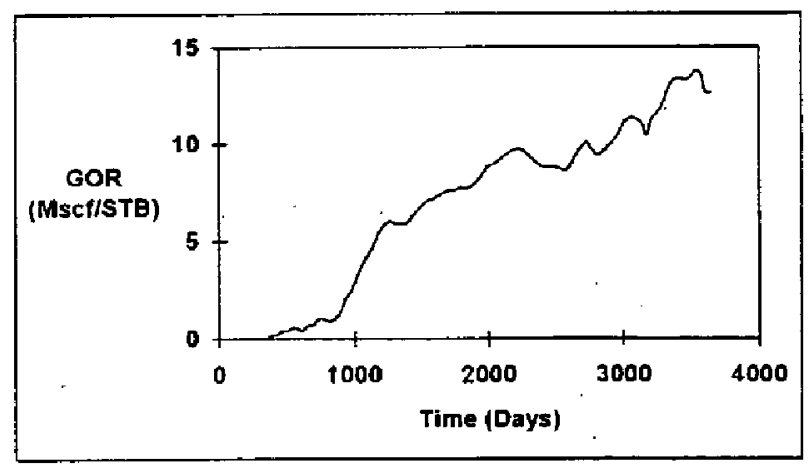

Figure 8: Free Gas Oil Ratio in Foam Base Case

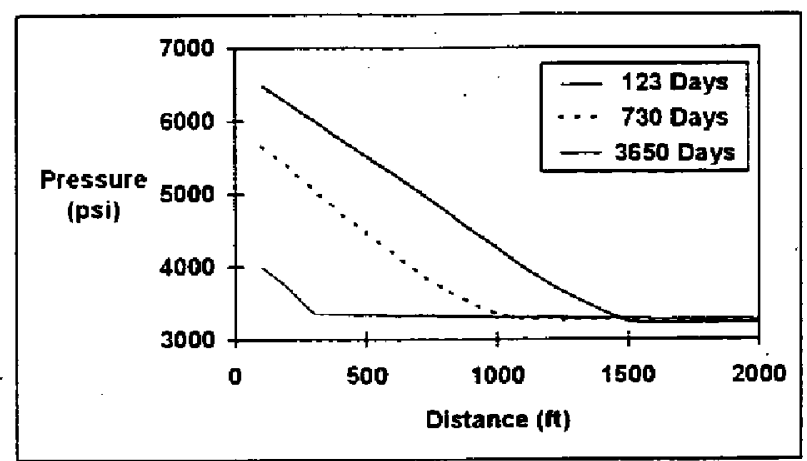

Figure 9: Foam Base Case Grid Block Pressure in Top Layer of Simulation Model 


\section{Injectivity and Foam Strength}

Clearly the injectivity problem needs to be considered further since it could prevent any in-depth foam treatments being implemented in practice. Reductions in the foam strength were considered. Run $B$ is equivalent to the base case except that the foam strength has been multiplied by a factor of 0.15 . The cumulative oil production is shown in Figure 10. The incremental oil recovery is reduced from 2.87 MMSTB to $2.17 \mathrm{MMSTB}$, Table 2 . However, the pressure in the injector grid blocks is reduced from 6500 psi to just $\$ 250$ psi, showing a significant improvement in injectivity. The reduction in the incremental oil is due to increased gas breakthrough along the top of the Etive. Further reduction in the foam strength leads to much more rapid gas breakthrough and significant reductions in the incremental oil produced.

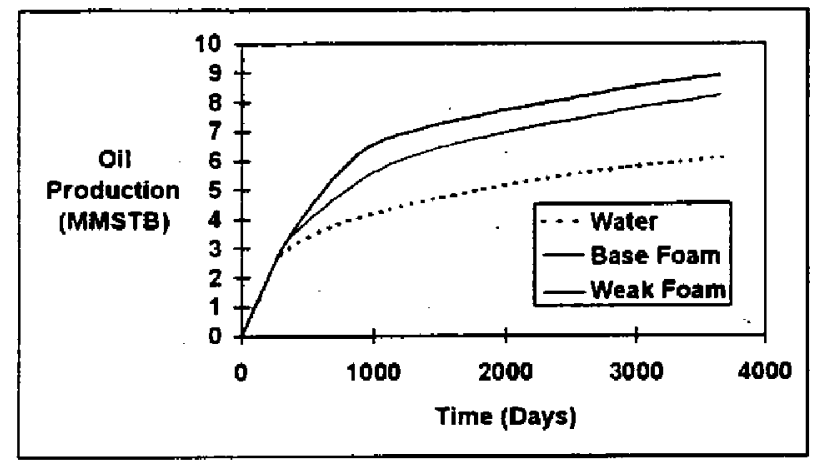

Figure 10: Cumulative Oil Recovery for Base Case Foam and Reduced Strength Foam

\section{Vertical Permeability}

Gravity effects had a significant impact on the placement of the foam. It might therefore be expected that lower $k_{v}: k_{h}$ values would lead to an improved performance. Run $\mathrm{C}$ considered the effect of reducing $\mathrm{k}_{v}: \mathrm{k}_{\mathrm{h}}$ from 0.1 to 0.01 (requiring the water and the foam flood to be run). The cumulative oil production for the water and foam flood is shown in Figure 11.

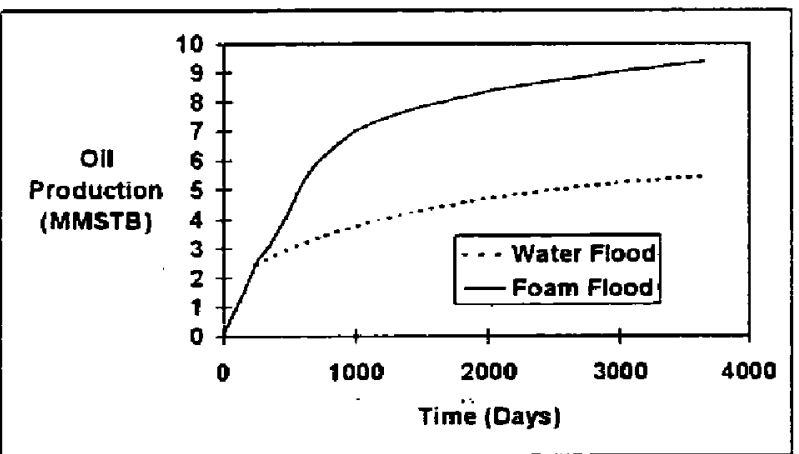

Figure 11: Cumulative Oil Recovery for Water and Foam Flood with $k_{v}: k_{n}=0.01$

The foam flood improved, with the cumulative recovery increasing from 8.96 MMSTB to 9.37 MMSTB compared to the $k_{\mathrm{v}}: k_{h}=0.1$ case, Table 2. Decreasing the vertical permeability reduced the water flood performance because there was less gravity slumping of water from the Etive into the upper layer of the Rannoch. These two changes combined led to an increase in the foam IOR from 2.87 to 3.91 MMSTB.

\section{Contribution from Flow Diversion}

The base case foam simulation allows for the residual oil saturation to be reduced from the water flood value of $25 \%$ to $10 \%$. A further simulation (Run D) was performed to examine the influence on the incremental recovery of maintaining the residual oil saturation to foam at $25 \%$. The cumulative oil recovery is shown in Figure 12, together with the base case foam flood and the water flood. The incremental recovery is reduced from 2.87 MMSTB to 1.54 MMSTB, Table 2, showing that approximately half of the increment is due to flow diversion alone.

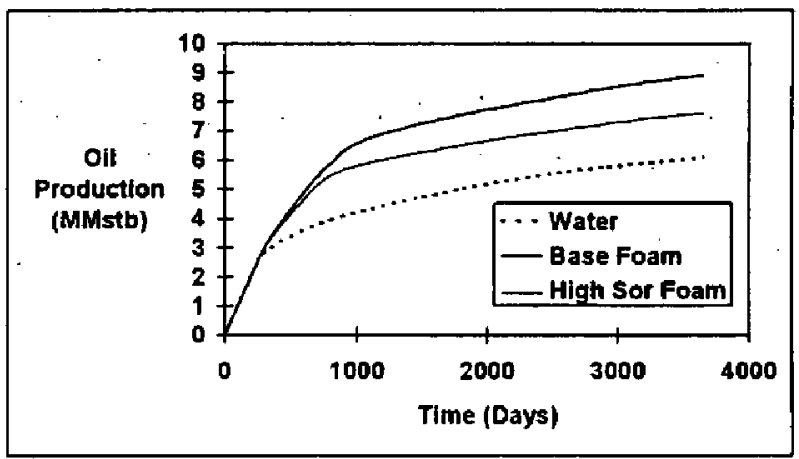

Figure 12: Cumulative Oil Recovery from Flow Diversion: Effect of $\mathbf{S}_{\text {org }}$

\section{Summary of Sensitivities}

The simulations presented highlight important two dimensional effects. Gravity slumping of the preinjected surfactant solution makes it difficult to form in adequate foam at the top of the Etive layer in ine model. Gravity drainage of surfactant solution in the foam invaded region also tends to weaken the foam at the top of the Etive layer. This allows gas breakthrough via this region of weaker foam. While it is possible to counter this effect by increasing the strength of the foam, this may increase the pressure required to drive the foam through the reservoir to unacceptable levels.

\section{CONCLUSIONS}

1. A simple analytical model has been used to highlight the potential benefits from IOR fluids that show selective mobility reduction as a function of permeability. 
2. A foam mobility model has been incorporated in the SCORPIO simulator allowing two and three dimensional simulations of foam injection to be performed.

3. Foam injection simulations have been performed using a cross-sectional model representative of the Rannoch-Etive formation of the North Sea:

4. Foam can improve recovery through a combination of flow diversion and reduction of residual oil saturation to water flooding

5. The performance of the foam is limited by gas breakthrough at the top of the Etive layer, as a result of gravity slumping of the pre-injected surfactant and drainage of water under gravity in the foam invaded region.

6. Gas breakthrough can be delayed by increasing the surfactant strength, but only at the expense of increasing the pressure required to drive the foam through the reservoir.

7. Shear thinning of the foam is important in reducing the pressure drop in the near well bore region

8. Lowering the $k_{v}: k_{h}$ ratio from 0.1 to 0.01 improves the performance of the foam

9. The study highlights the importance of gravity effects and injectivity issues in foam injection.

\section{ACKNOWLEDGEMENTS}

This work was supported by the UK Department of Trade and Industry as part of its programme of IOR studies at AEA Technology. The authors thank Dr T.P Fishlock for useful discussions.

\section{NOMENCLATURE}

\author{
$f_{g} \quad$ gas fractional flow (-) \\ $f_{g}^{*} \quad$ reference gas fractional flow (-) \\ $h_{i} \quad$ fraction of total thickness in layer i $(-)$ \\ $k_{i} \quad$ permeability in layer $\mathrm{i}\left(\mathrm{m}^{2}\right)$ \\ $l_{i} \quad$ fractional distance penetrated by displacement \\ front in layer $i(-)$ \\ $1:$ fractional distance penëtrated in layer 2 at \\ breakthrough in layer $1(-)$ \\ $n \quad$ foam coalescence exponent \\ $t$ dimensionless time (-) \\ $u_{3} \quad$ gas phase Darcy velocity $(\mathrm{m} / \mathrm{s})$ \\ $\lambda$, oil relative mobility (1/Pa.s)
}

$\lambda_{i} \quad$ displacing phase relative mobility in layer $\mathrm{i}$ (1/Pa.s)

$\lambda_{r \alpha}$ relative mobility of phase $\alpha$ (1/Pa.s)

$\lambda_{r \alpha}^{*}$ reference relative mobility of phase $\alpha$ (1/Pa.s)

$\lambda_{r g 1}^{*}$ reference gas relative mobility coefficient (1/Pa.s)

$\lambda_{\mathrm{rg} 2}^{*}$ reference gas relative mobility coefficient (1/Pa.m)

\section{REFERENCES}

1. I E Hanssen, $T$ Holt and $L M$ Surguchev, "Foam Processes: An Assessment of their Potential in North Sea Reservoirs Based on a Critical Evaluation of Current Field Experience", SPE/DOE 27768, presented at the SPE/DOE Ninth Symposium on Improved Oil Recovery, 17-20 April 194, Tulsa, OK.

2. Z I Khatib, G J Hirasaki and A H Falls, "Effects of Capillary Pressure on Coalescence and Phase Mobilities in Foams Flowing Through Porous Media" SPE 15442, presented at the 1986 SPE Annual Technical Conference and Exhibition, New Orleans, October 5-8.

3. A W Fisher, R W S Foulser and S G Goodyear, "Mathematical Modelling of Foam Flooding", SPE/DOE 20195, presented at the SPE/DOE Seventh Symposium on Enhanced Oil Recovery, 17-20 April, Tulsa, OK.

4. A H Falls, P A Gauglitz, G J Hirasaki, D D Miller, T W Patzek and T W Ratulowski, "Development of a Mechanistic Foam Simulator: The Population Balance and Generation by Snap-off", SPE/DOE 14961, presented at the SPE/DOE Fifth Symposium on Enhanced Oil Recovery, 20-23 April, Tulsa, OK.

5. T Scott, S R Sharpe, K S Sorbie, P J Clifford, L J Roberts. R W S Foulser and J A Oakes, "A General Purpose Chemical Flood Simulator", SPE16029, presented at the 9th SPE Symposium on Reservoir Simulation. San Antonio, TX, 1-4 February 1987

6. S H Raza, "Foam in Porous Media: Characteristics and Potential Applications", SPEJ (December 1970) 328-336. Trans., AME, 249.

7. A I Jimenez and C J Radke, "Dynamic Stability of Foam Lamellae Flowing Through a Periodically Constricted Pore", Chapter 25, Oil-Field Chemistry, ACS Symposium Series 396, 1989: pp460-479. 
8. J E Hanssen, $L$ M Surguchev, I Svorstol and T Blaker, "SAGA Injection: A New Combination IOR Process for Stratified Reservoirs", presented at the 7th European IOR Symposium, Moscow, Russia, 27-29 October 1993. 